\title{
WILDLIFE ART AND ILLUSTRATION: STONE SCULPTURE AND PAINTING - SOME EXPERIMENTS IN AUROVILLE, TAMIL NADU, INDIA
}

\section{Eric Ramanujam ${ }^{1} \&$ S. Joss Brooks ${ }^{2}$}

${ }^{1}$ Principal Investigator (Faunistics), ${ }^{2}$ Director, Pitchandikulam Bioresource Centre / Pitchandikulam Forest Consultants, Auroville, Tamil Nadu, India

${ }^{1}$ ericramanujamowl@yahoo.com (corresponding author), ${ }^{2}$ joss@auroville.org.in

Abstract: The métier of combining granite stone carving with painting of wildlife subjects in Pitchandikulam at Auroville International Township has been rather innovative, and some works are described and analyzed. The basic history of stone carving, and especially of those sculptures with animal motifs, is recounted, and the applications, especially in the context of enhancing landscape architecture, are discussed and highlighted.

Keywords: 3 ds Max, landscape architecture, outdoor public space, petroglyph.

DOI: http://dx.doi.org/10.11609/JoTT.03925.6355-62

Editor: Stephen D. Nash, Conservation International, Stony Brook, USA

Date of publication: 26 September 2014 (online \& print)

Manuscript details: Ms \# 03925 | Received 23 January 2014 | Final received 25 August 2014 | Finally accepted 01 September 2014

Citation: Ramanujam, M.E. \& S.J. Brooks (2014). Wildlife art and illustration: stone sculpture and painting - some experiments in Auroville, Tamil Nadu, India. Journal of Threatened Taxa 6(10): 6355-6362; http://dx.doi.org/10.11609/JoTT.03925.6355-62

Copyright: ( Ramanujam \& Brooks 2014. Creative Commons Attribution 4.0 International License. JoTT allows unrestricted use of this article in any medium, reproduction and distribution by providing adequate credit to the authors and the source of publication.

Funding: Chennai Rivers Restoration Trust (CRRT) \& WIPRO Technologies

Competing Interest: The authors declare no competing interests.

Author Details: M. ERIC RAMANUJAM has been a wildlife illustrator for over two decades and has a background in the advertising industry. Since 1997 he has been involved in full time conservation and has been part of a team which undertook wildlife surveys in the Kaliveli region near Puducherry, Eastern Ghats and Adyar wetland complex in Chennai. His main sphere of interest is the natural history of the Indian Eagle Owl Bubo bengalensis. S. Joss BRooks established Pitchandikulam, a forest community in Auroville, and was one of the pioneers of re-establishing the indigenous coastal vegetation of the region. He was the lead consultant to the prestigious Government of Tamil Nadu's Adyar Poonga wetland restoration project in Chennai. He is the recipient of the Dr. Triloki Nath Khoshoo Award in 2010 for his contribution to eco-restoration initiatives.

Author Contribution: SJB evolved the concept of painting and carving wildlife in stone. MER undertook the preparation of the sculptures, and prepared the manuscript with inputs from SJB.

Acknowledgements: Chennai Rivers Restoration Trust (CRRT) \& WIPRO Technologies

\section{PITCHANDIKULAM}

FOREST 
Petroglyphs are older than human civilizations - the earliest known examples date back to the time of the Upper Paleolithic or Late Stone Age $(50,000-10,000$ years ago). Engravings on flat pieces of stone were found in considerable numbers-more than 5,000 at one Spanish cave site-with marks so faint that the technique was closer to drawing than to sculpture and were not spotted by the early excavators, but were discovered much later in 'spoil heaps' (Breuil \& Kirchner 1970; Clottes 2010). The earliest known three-dimensional sculptures were of human form (for example, the "Venus of Hohle Fels" that dates back to 40,000 BC and the "Venus of Willendorf" to around $30,000 \mathrm{BC}$ ), but later cultures created animal and human/animal forms in stone (Liebson 1991). The earliest such artworks were produced using abrasive techniques, but for most of human history the hammer and chisel were the basic tools for carving stone. Modern technology has provided pneumatic hammers, drills and other devices, which make it possible for artists to be more creative and to speed up what used to be, at an earlier period, a time-consuming and physically strenuous endeavour.

The production of the sculpture begins with the selection of the stone for carving. Some sculptors use the stone itself for inspiration, while others begin with a form already in mind, and find the right stone to realize their vision. The latter was the preferred method of Michelangelo di Lodovico Buonarroti Simoni who claimed that his job was to free the form trapped inside the 'block', as whatever was inside was already there, and it was his responsibility to remove what did not belong in order to reveal the true beauty within, and his single-minded searches of the various marble quarries to choose the exact stones to represent his concepts are well-documented (Scigliano 2012). This is contrary to the often-repeated stories that he developed his concepts according to the shape of the stones he acquired <en.wikipedia.org/wiki/stone carving> <http://dawnarobertson.weebly.com/wildlifesoapstone-portfolio.html>

Being a subtractive medium, stone sculpture is demanding and fraught with a lot of risk - with clay or wax modelling one can both add and take away, but with stone one can only take away and a single mistake can irretrievably destroy many hours of hard labour. Because of this, sculptors usually pay great attention to the design phase and make a series of detailed sketches (studies) and / or maquettes before even touching the stone - which in the rough form itself can be quite expensive (especially if marble is involved). In these days of superior technology many artists use software like $3 \mathrm{ds}$
Max which provides a comprehensive solution for threedimensional modelling, rendering and composing, which is ideally suited to graphic artists, and new versions like 3ds Max 2014 have new tools for particle animation and perspective matching.

The sculptor usually begins by knocking off large pieces of unwanted stone (the 'roughing-out' phase) until the block assumes the overall shape of the envisioned statue. Once the general shape has been established, other tools are used to refine the image. Scraping tools are then used to enhance the shape into its final form, and nowadays abrasives attached to machine tools have made a huge difference to what at one time used to be quite a laborious process. Finally, a device called a riffler is used to create fine textural details like scales, hair, etc.

Common subjects for animal sculptures in prehistoric times included animals that were hunted, like reindeer, horses, bison and mammoths, as well as animals that were not, such as lions and other big cats, bears and woolly rhinoceros. This is clear evidence of behavioural modernity: the appearance of art in the past helps us define what makes us human, and is part of what we are or what we can be (Gabora 2007; Williams 2011).

Animal and human/animal motifs in rock were an integral feature of the art of ancient civilizations. The Egyptians were probably the best-known stone carvers (Stevenson et al. 1998), but monumental stone carvings of animals also existed in ancient India, western Asia and South America (Grigson 1977; Gruzinski 1992; Ascalone 2007). However, true representations of animals began in Greece during the Hellinistic Period (around 31BC) when common people and animals became acceptable subjects for sculpture and were commissioned by wealthy families for adornment of their homes and gardens (Boardman 1989; Burn 2005; Havelock 1968). The Romans were, in their turn, influenced by Greek art and they made it more dramatic - good examples are Trajan's Column and Hadrian's Triumphal Arch, both of which have animal motifs carved into them (Toynbee 1971; Kleiner 2007). Nevertheless, it is difficult to distinguish between Greek and Roman art because most sculptors of those times were Greek (Henig 1983). It is surprising that, except for horses and domestic livestock, animals did not feature prominently in sculpture during the Renaissance (Olson 1992) - even the great Michelangelo used an owl only as an adjunct symbol of 'night time' in his sculpture of a reclining female nude (Morris 2009). Even today, in spite of wildlife artists like Pati Stajcar, Martyn Bednarczuk, Ed Walicki and Clifford Frederick working in stone, we do not know of any working specifically with granite. 
We use granite as the principal base material, and add paint to lend colour to the animals. Granite is the chosen material because most of the sculptures are designed for outdoor public spaces, and softer stones would be damaged by long-term exposure to the elements. This is one innovation (that is, combining painting with sculpture in stone) that does not have a precedent to the best of our knowledge, and our experiments in Pitchandikulam have proven to be worthwhile, and the results found to be very satisfactory.

However, one must say that paint fades, especially when exposed to direct sunlight. The phenomenon of pigments fading when exposed to infra-red and ultraviolet light has been an eternal problem in outdoor spaces. David Roberts (1796-1864), an 'orientalist', depicted in a number of his lithographs brightly-painted freshly-unearthed Egyptian sculptures which have today lost almost all traces of paint. Non-fading paints are available, but due to their non-malleability and limited range of colors are not suitable for this type of work. Oils showed some promise, in spite of being time consuming to work with, but fungal encrustations occurred during wet weather and damaged the painted surfaces. The most effective are standard enamel paints which are malleable, fast drying and allow fine rendering of detail. At one time we did try coating the painted surface with transparent varnish, but the paintings changed color and hence the exercise had to be discontinued.

\section{GENRES OF WILDLIFE CARVING AND PAINTING}

Engraving and painting: This genre is influenced by ancient petroglyphs - for example the Saharan rock carving of a recumbent antelope from southern Algeria, and the carvings of various creatures from 'Laxe dos carballos' in Campo Lameiro. The technique is very simplistic: incised outlines in stone with painted interiors.

Two-dimensional carving and painting: Here the onus is on creating a shape. Only part of the stone is removed, and the figures in relief are painted over.

Three-dimensional carving and painting: This involves removal of large quantities of stone and is an exacting process. The design phase itself is quite challenging, and both traditional methods as well as $3 \mathrm{ds}$ Max are employed.

An intermediate phase: Sometimes it is possible to relatively little stone to give a realistic three-dimensional perspective, especially when subjects like geckos are concerned, because these creatures appear as such in nature.

\section{APPLICATIONS}

As mentioned earlier, most of the work has been created to enhance landscape architecture, but a few pieces have been purposefully designed as collectors' items.

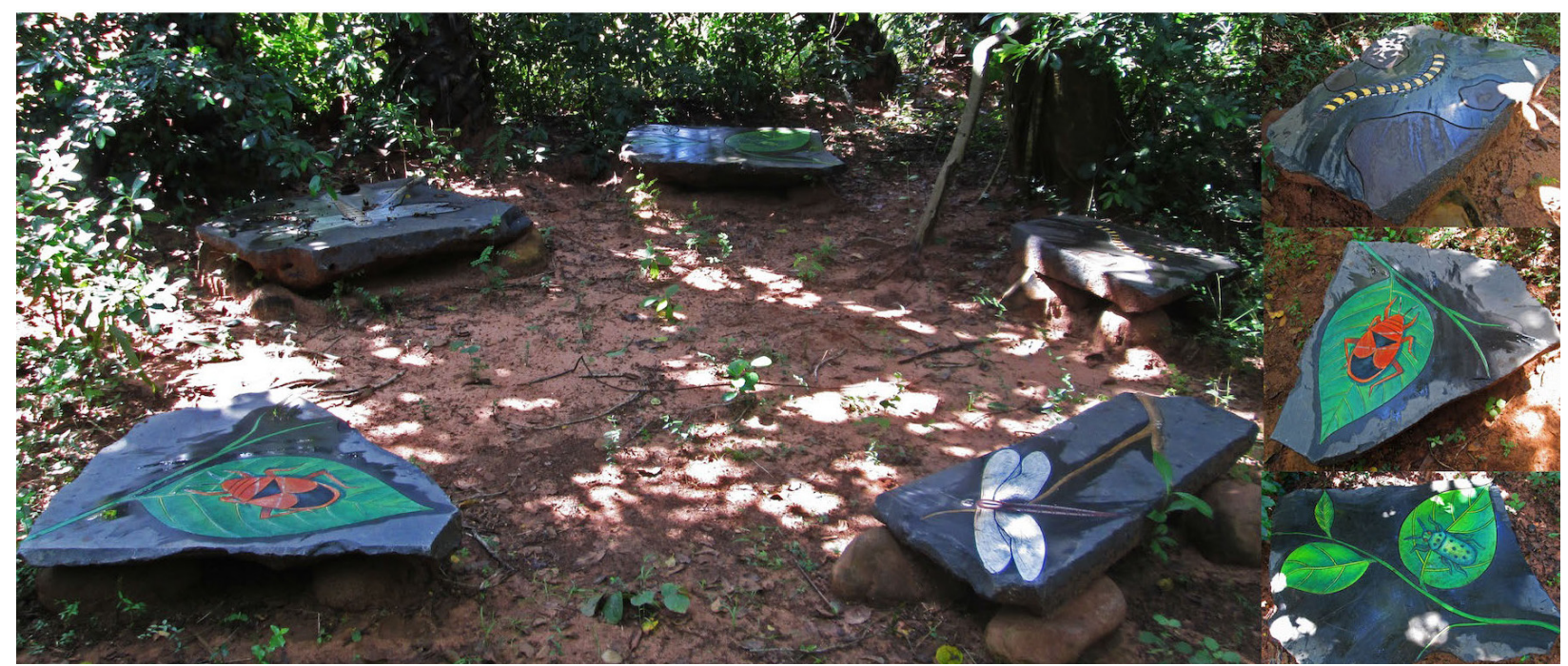

Image 1. Simple engraving and painting on stone was employed in this seating arrangement. Creatures depicted: Centipede Scolopendra hardwickii, Stainer Bug Iphita sp. and Jewel Bug Chrysocornis sp. A Club Tail Dragonfly Ictinigomphus sp. is also visible in the foreground. Pitchandikulam, Auroville. 


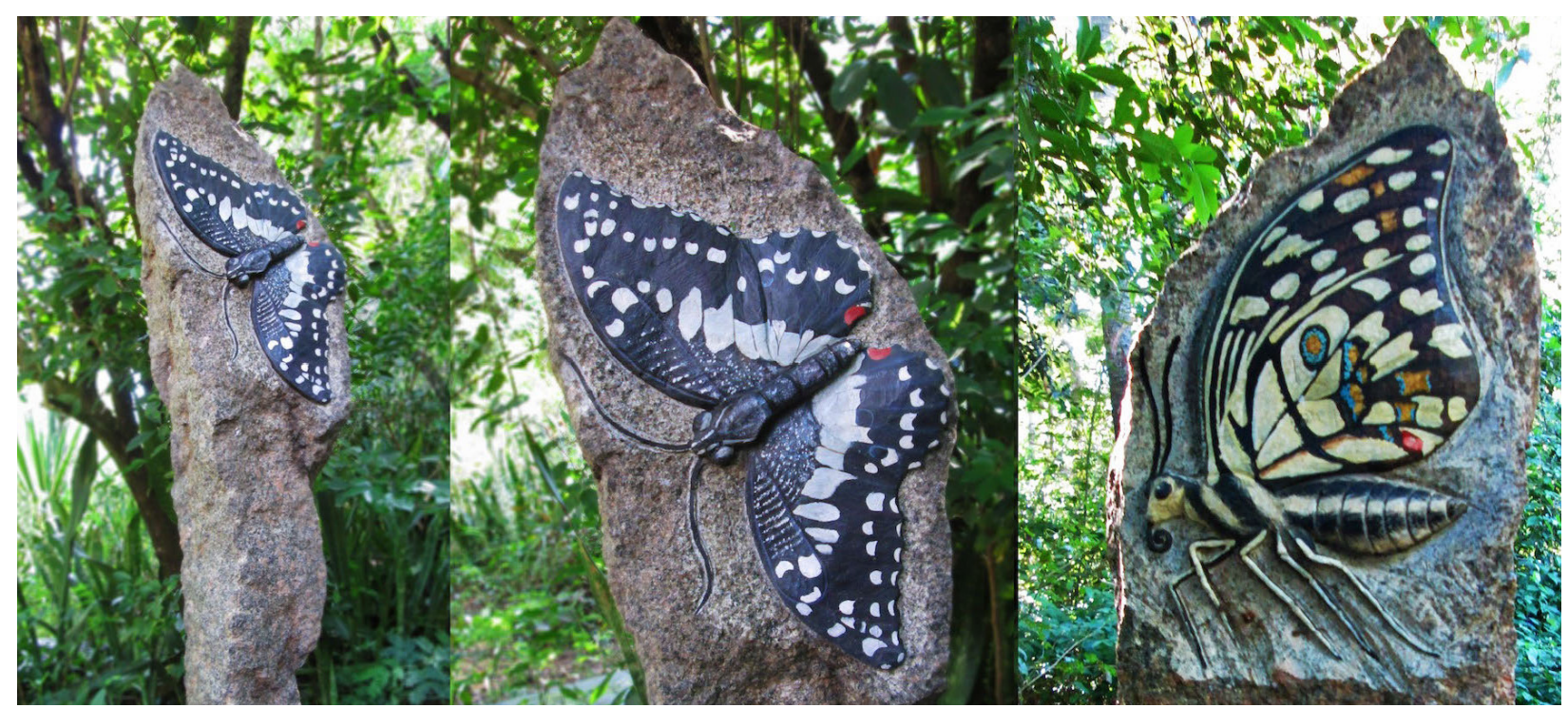

Image 2. Two-dimensional carving and painting of a Common Lime Butterfly Papilio demoleus on an oddly-shaped pillar. Sometimes one comes upon oddly-shaped pillars like this and we usually find a subject to suit it. So, occasionally, the shape and size of the pillars influence the design. The reverse side of the pillar has the same species in a resting posture. Pitchandikulam, Auroville.

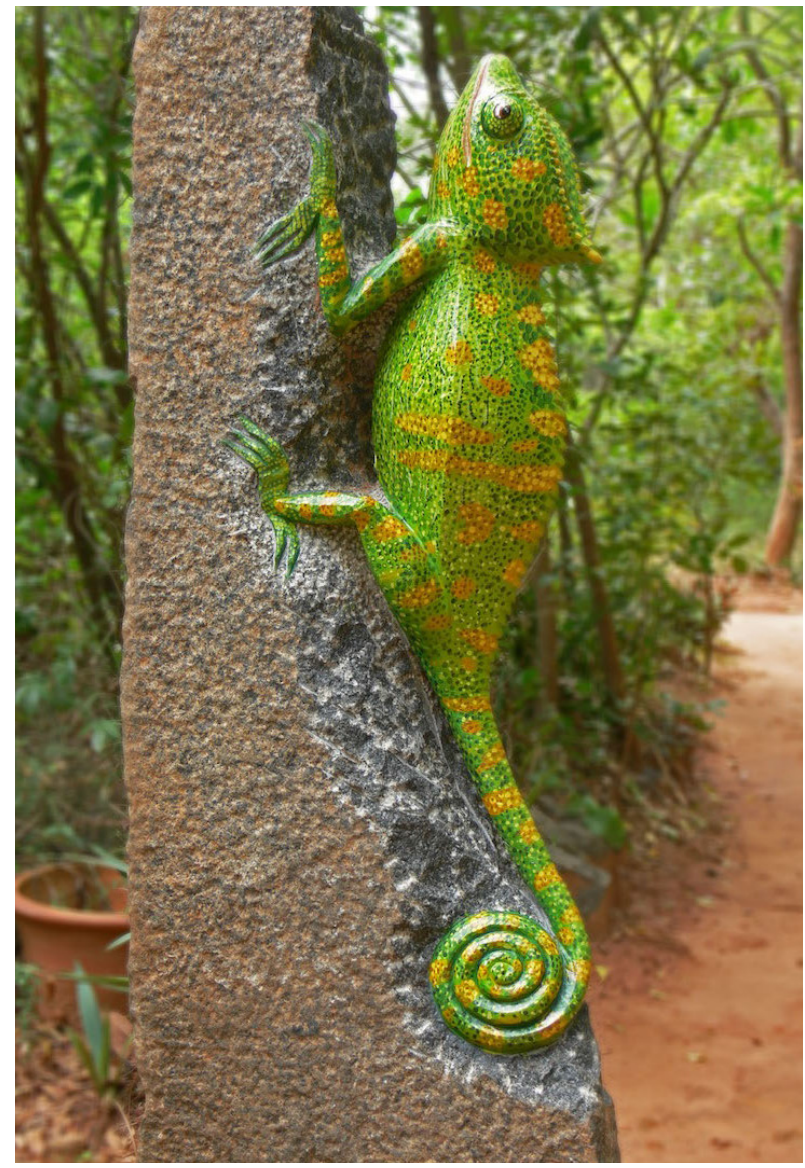

Image 3. A three-dimensional carving of a Chameleon Chamaeleon zeylanicus exhibiting bright colouration. This sort of carving necessitates the removal of large quantities of stone. Pichandikulam, Auroville.

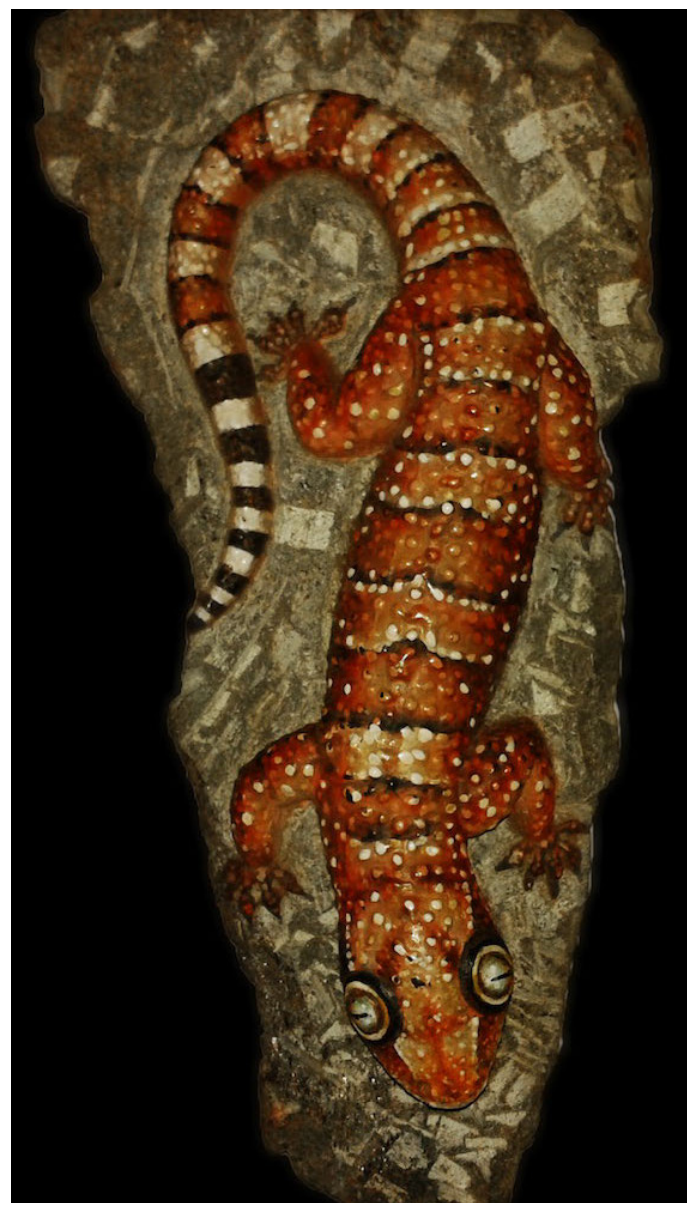

Image 4. An intermediate stage of a carving depicting a Termite Hill Gecko Hemidactylus triedrus. Private collection of Payal Bojwani Molur. 


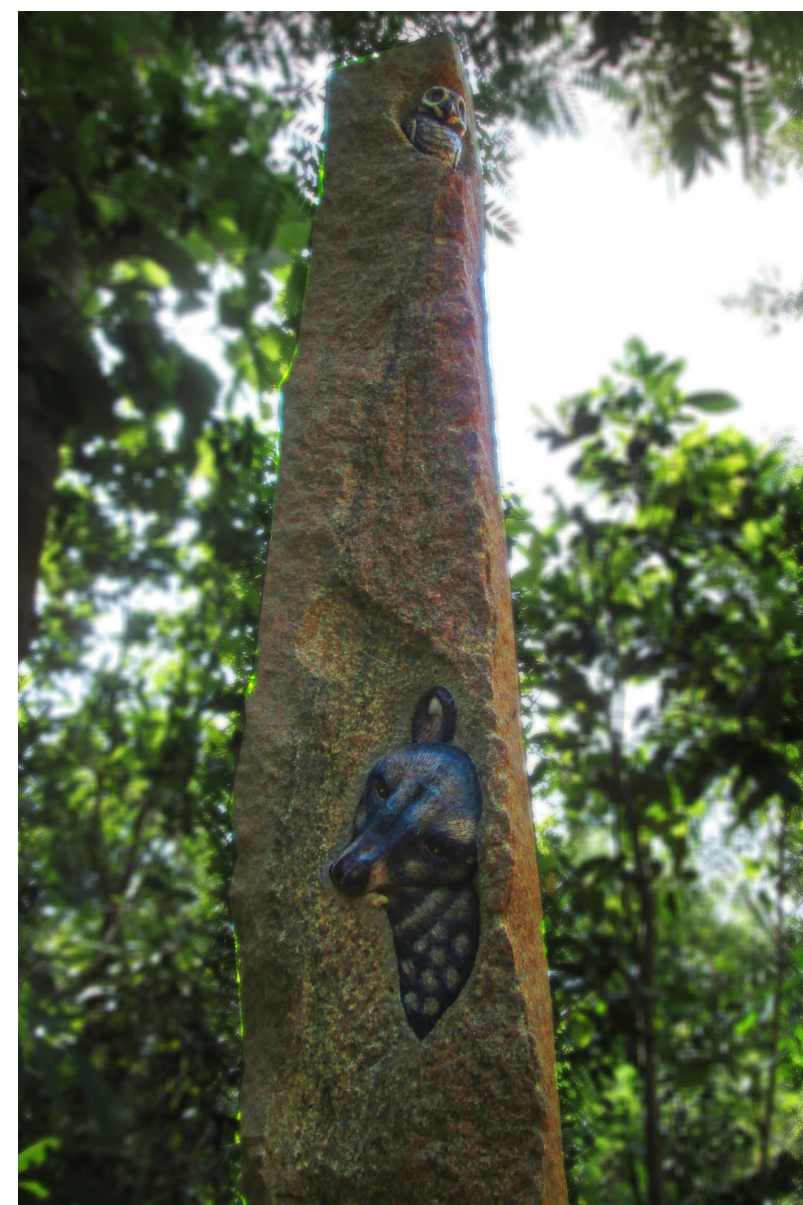

Image 5. A carved pillar with a Spotted Owlet Athene brama and the head of a Common Palm Civet or Toddy Cat Paradoxurus hermaphroditus. Pitchandikulam, Auroville.

Pillars: The most frequently-used element to enhance landscape architecture is the carved pillar. Some of these works are quite difficult to execute, especially when the pillars are $15 \mathrm{ft}$ tall and weigh many tonnes, but they are especially impressive when grouped together.

Directional signage: Grooves are cut into some pillars and directional signage on planks bolted on.

Benches: Carving has been used to embellish seating, especially in public spaces where human amenities are the main concern.

Plaques: One innovative feature is the use of carved boulders to accommodate commemorative plaques. These are especially effective and impressive when dignitaries are called upon to inaugurate prestigious government projects like the Adyar Eco Park.

Collectors' items: We believe painted stone carving is an art in its own right, and some artists now concentrate upon working in their studios and exhibiting the resulting works in galleries. Often, the items prepared for such

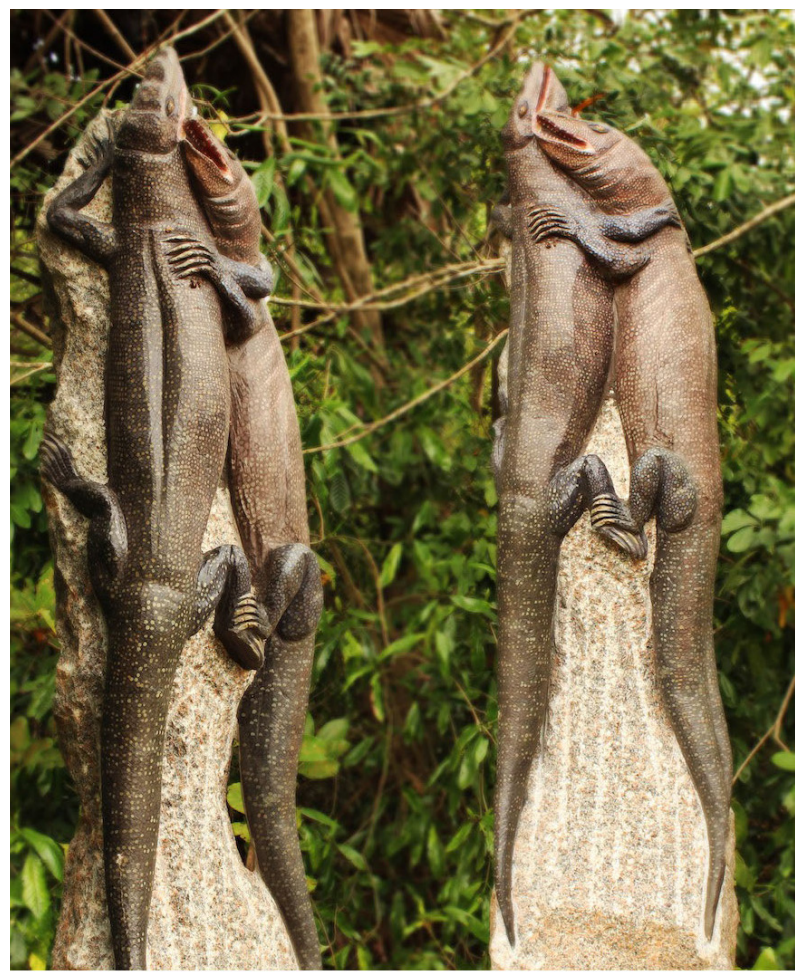

Image 6. A carved pillar depicting Indian Monitors Varanus bengalensis in combat. Pitchandikulam, Auroville.

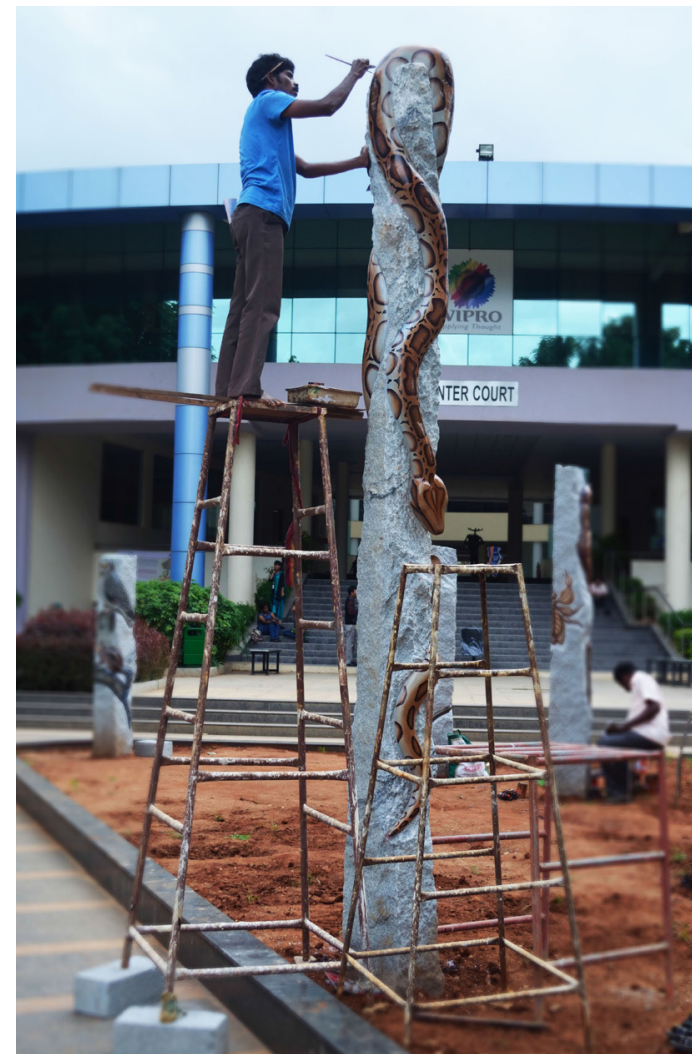

Image 7. An artist working on a $7 \mathrm{~m}$ long Indian Python Python molurus. Such work is rather time-consuming and can be hazardous. WIPRO Technologies, Electronic City, Bengaluru. 


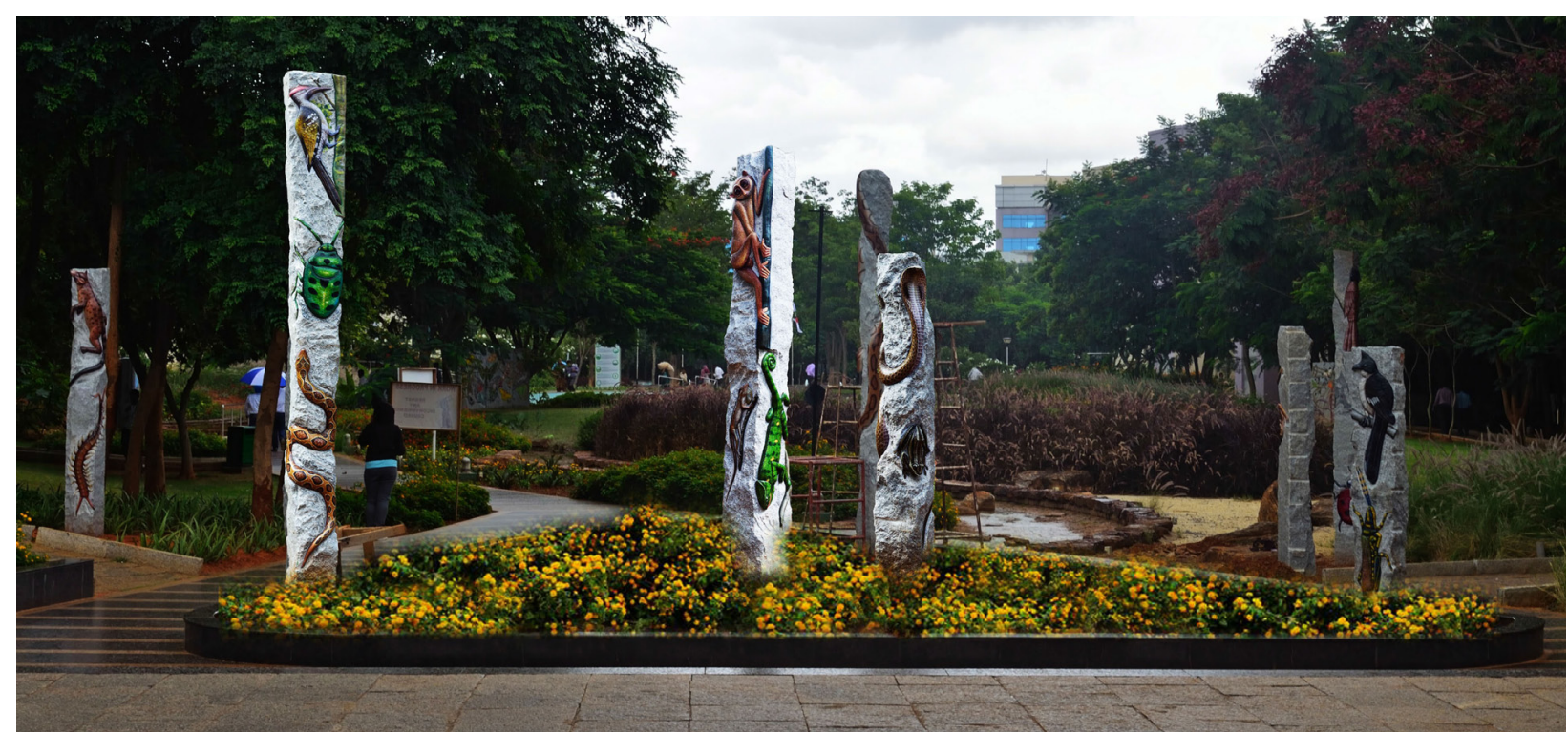

Image 8. A combination of pillars of different heights is especially eye-catching. Creatures visible from this angle: Common Palm Civet Paradoxurus hermaphrodites, Centipede Scolopendra sp., Black-rumped Flameback Woodpecker Dinopium benghalense, Jewel Bug Chrysocornis sp., Russell's Viper Daboia russelii, Slender Loris Loris lydekkerianus, Fan-throated Lizard Sitana ponticeriana, Chameleon Chamaeleon zeylanicus, Spectacled Cobra Naja naja, Common Tree Frog Polypedates maculates, Pied Cuckoo Clamator jacobinus and Painted Grasshopper Poecilocera pictus. WIPRO Technologies, Electronic City, Bengeluru.

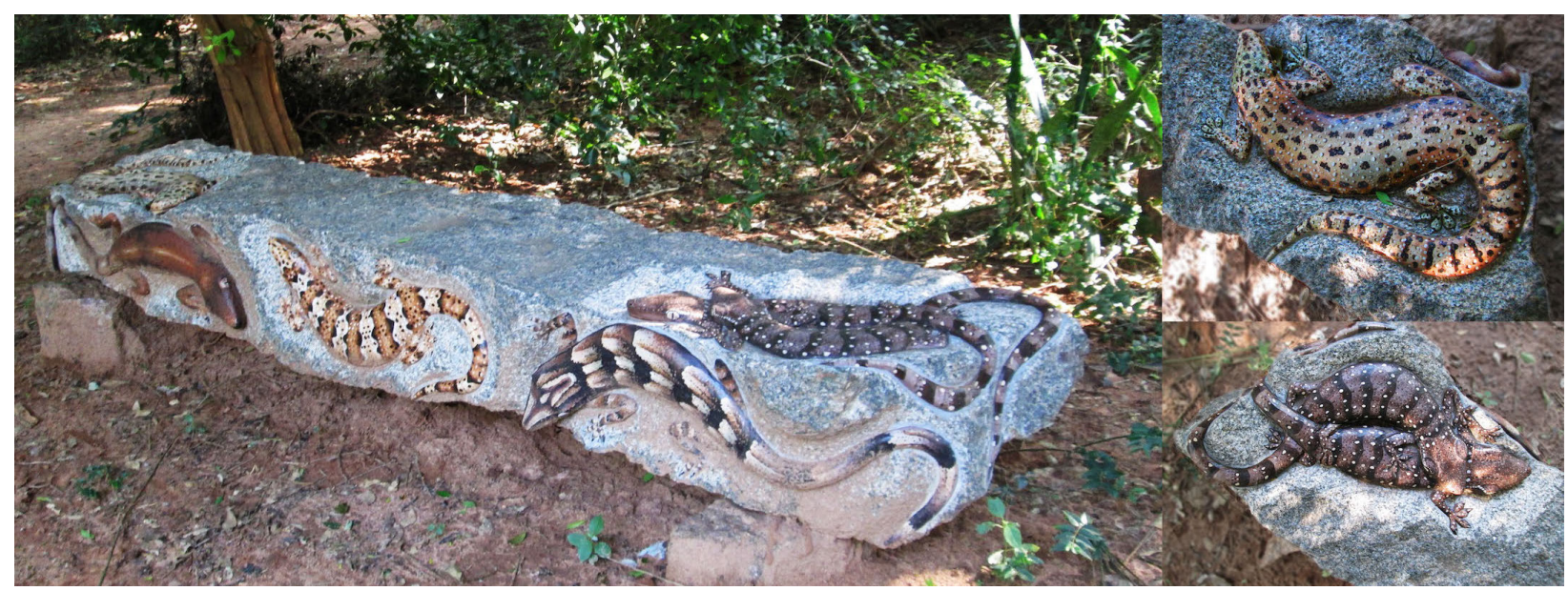

Image 9. A bench with the four commonly found geckos of the Coromandel Coast, viz., Southern House Gecko Hemidactylus frenatus, Brook's Gecko H. brooki, Bark Gecko H. leschenaulti and Termite Hill Gecko H. triedrus. Pitchandikulam, Auroville.

display have been thoroughly researched, designed and executed in such detail that every scale, feather and hair is replicated to scientific exactitude.

To the purist, painting stone may be anathema, but we wish to point out that we paint only the relevant portions, that is, the subject itself, and leave the rest of the surrounding medium to exhibit its natural beauty and colours. Today, wildlife art appears to be in the grip of a tendency towards schematization which is cramping artistic expression, so that new trends charged with living tension are becoming increasingly rare. If zoomorphic representation is to survive in this age of photography and cinematography, newer trends must be encouraged and sustained. This does not mean that wildlife art has to lean towards abstractionism / other forms of modernistic art, but rather that it has to become more user friendly and functional. The experiments in Pitchandikulam have attempted to address exactly such a situation, that is, art for outdoor public areas intended to enhance landscape architecture, and for 


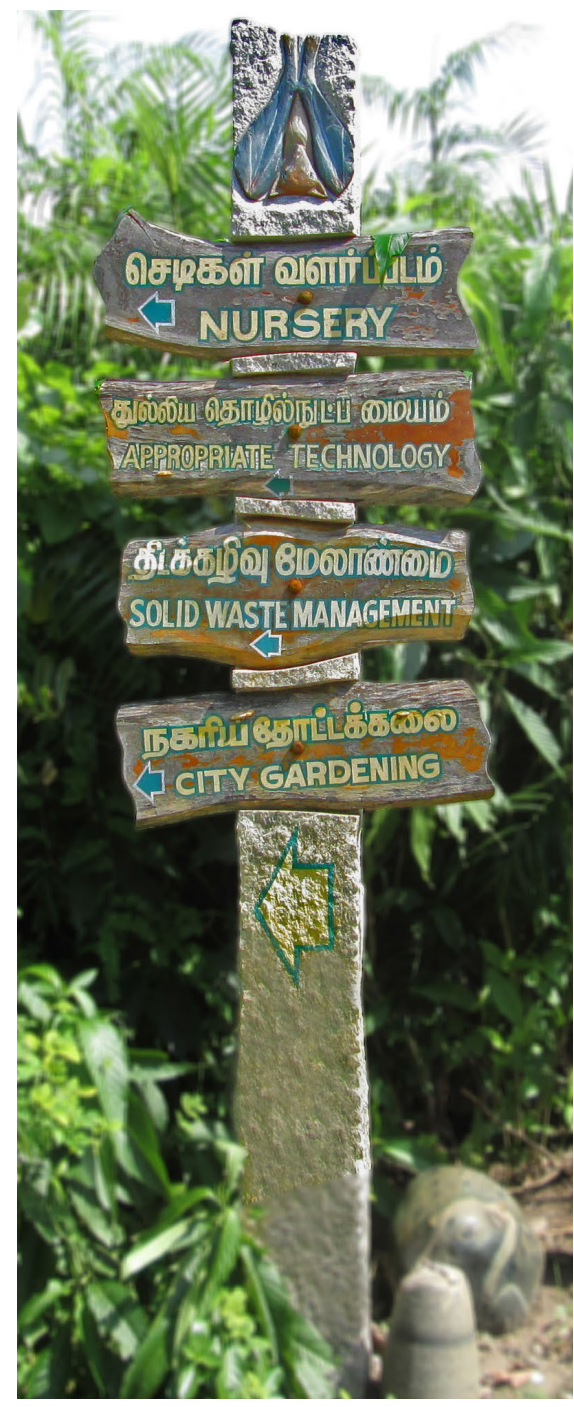

Image 10. A directional sign with a Short-nosed Fruit Bat Cynopterus sphinx carved at the top. Adyar Eco Park, Chennai.

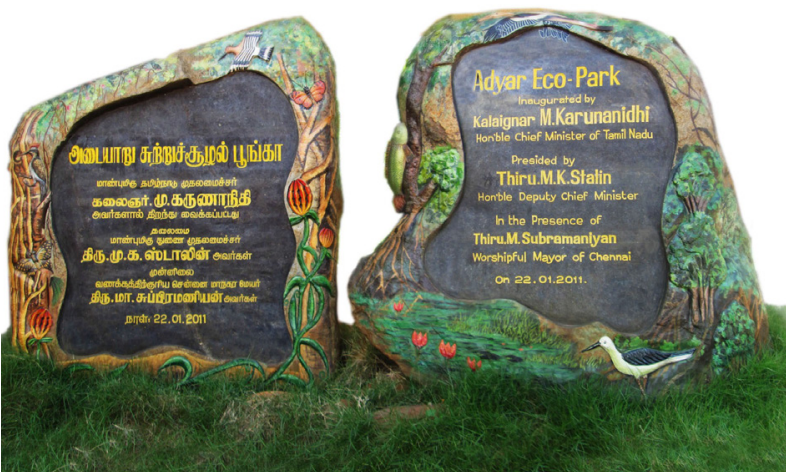

Image 11. These are large stones with carvings and paintings of wildlife and vegetation designed for the then Chief Minister of Tamil Nadu, M. Karunanidhi's inauguration of the Adyar Eco Park. Wildlife depicted: Black-rumped Flameback Woodpecker Dinopium benghalense, Hoopoe Upupa epops, Lime Butterfly Papilio demoleus, Peacock Pansy Junonia almanae, Climbing Perch Anabas testudineus, Painted Stork Mycteria leucocephala and Black-winged Stilt Himantopus himantopus. Adyar Eco Park, Chennai.

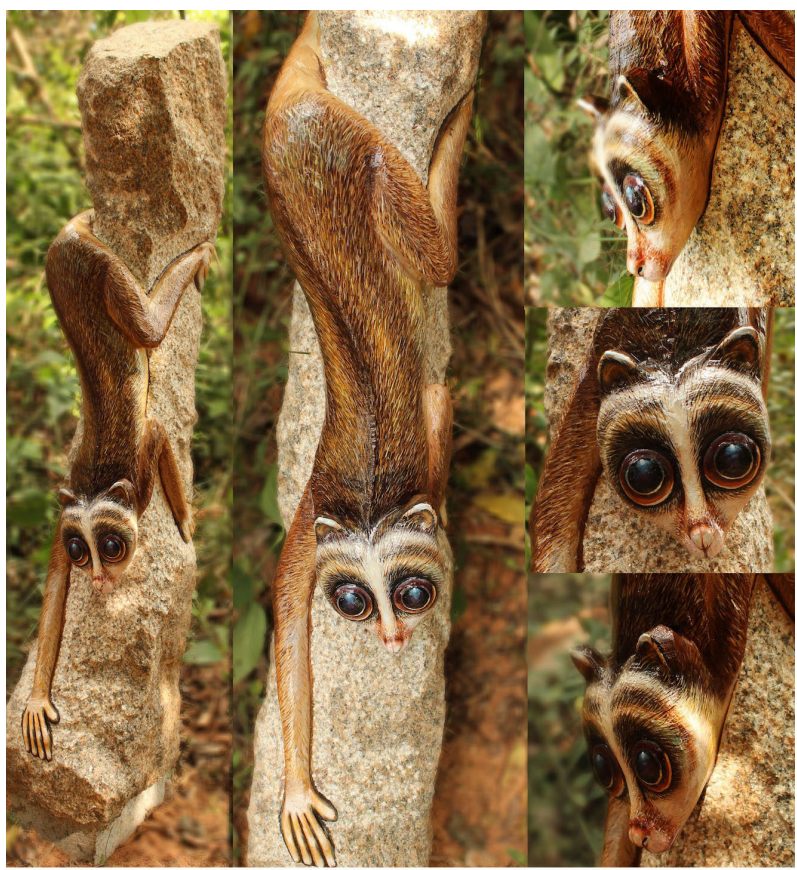

Image 12. A fine carving and finer painting of a Slender Loris Loris lydekkerianus. Every hair has been meticulously painted, and the animal is very lifelike. Pitchandikulam, Auroville.

the connoisseur, a piece of scientific art in a favourite personal space.

\section{REFERENCES}

Ascalone, E. (2007). Mesopotamia: Assyrians, Sumerians, Babylonians (Dictionaries of Civilizations 1). University of California Press, Berkeley.

Breuil, H. \& B. Kirchner (1970). Franco-Cantabrian Rock Art, pp. 10-65. In: The Art of the Stone Age. Methuen, London, 287pp.

Clottes, J. (2010). Cave Art. Phaidon Press Ltd, London, 330pp.

Gabora, L. (2007). Mind: What archaeology can tell us about the origins of human cognition, pp. 283-296. In: Mind - Handbook of Theories and Methods in Archaeology. Altamira Press, Walnut Creek.

Grigson, C. (1977). Some thoughts on Unicorns and Other Cattle Depicted at Mohenjo-daro and Harappa. South Asian Archaeology, pp. 166-169.

Gruzinski, S. (1992). The Aztecs: The Rise and Fall of an Empire. Harry N. Abrams, London.

Henig, M. (1983). A Handbook of Roman Art. Phaidon Press Ltd., London

Kleiner, F.S. (2007). A History of Roman Art. Harry N. Abrams, New York.

Liebson, M. (1991). Direct Stone Sculpture. Schiffer Publishing, 160pp. Morris, D. (2009). Owl. Reaktion Books, 216pp.

Olson, R.J.M. (1992). Italian Renaissance Sculpture. Thames \& Hudson. Scigliano, E. (2012). Michelangelo's Mountain: The Quest for Perfection in the Marble Quarries of Carrara. Atria Books, 368pp.

Stevenson, S.W., R. Simpson \& W. Kelly (1998). The Art and Architecture of Ancient Egypt. $3^{\text {rd }}$ Edition. Yale University Press, 501pp

Toynbee, J.M.C. (1971). Roman Art. The Classical Review 21: 439-442.

Williams, D.L. (2011). The Mind in the Cave: Consciousness and the Origins of Art. Thames \& Hudson Ltd., London, 320pp. 


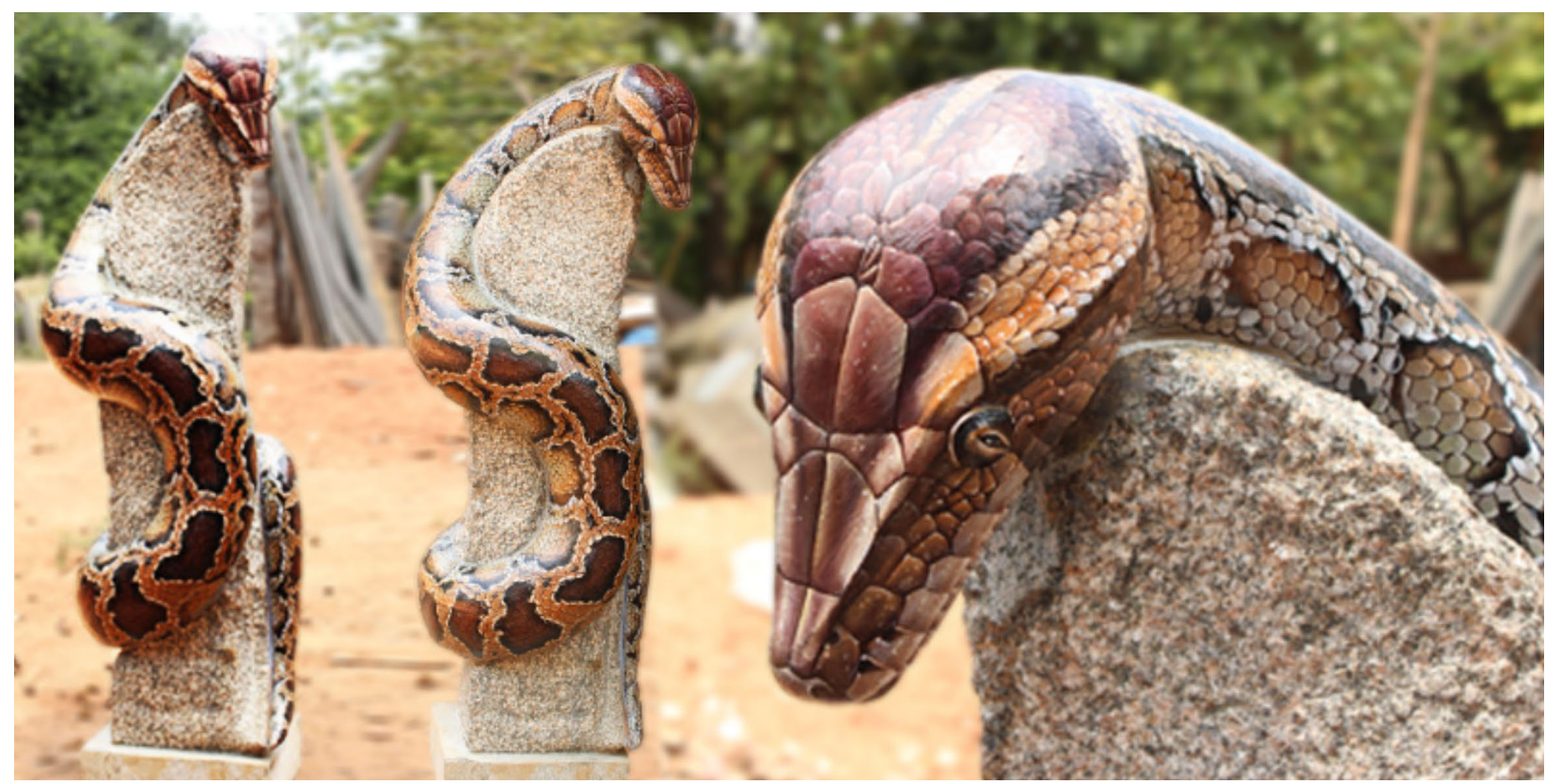

Image 13. A fine carving and painting of an Indian Python Python molurus, about $8 \mathrm{ft}$ long. Every scale has been reproduced in scientific detail. Pitchandikulam, Auroville.

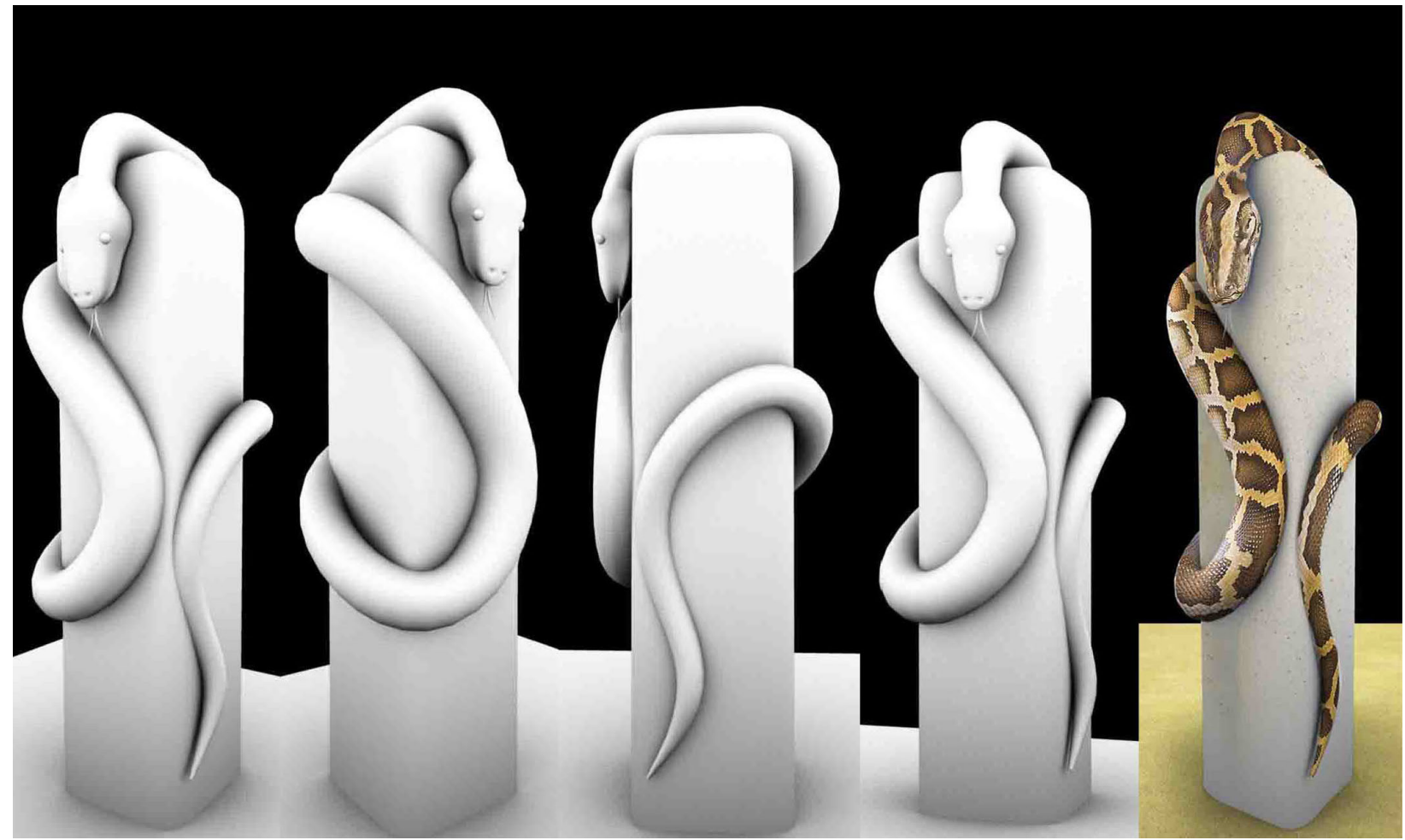

Image 14. Three-dimensional carving is an exacting process in itself but the design phase is also crucial in order to produce a satisfactory result. Shown here are $3 \mathrm{ds}$ Max images which helped with the planning of the sculpture of the python. 